\title{
Analisis Heteroskedastisitas Pada Data Cross Section dengan White Heteroscedasticity Test dan Weighted Least Squares
}

\author{
Christalia A. Mokosolang ${ }^{1}$, Jantje D. Prang ${ }^{2}$, Mans L. Mananohas ${ }^{3}$ \\ ${ }^{1}$ Program Studi Matematika, FMIPA, UNSRAT Manado, mchristalia@yahoo.co.id \\ ${ }^{2}$ Program Studi Matematika, FMIPA, UNSRAT Manado, jantjedprang@yahoo.com \\ ${ }^{3}$ Program Studi Matematika, FMIPA, UNSRAT Manado, mansmananohas@ yahoo.com
}

\begin{abstract}
Abstrak
Tujuan dari penelitian ini yaitu untuk menganalisis dan mengatasi pelanggaran asumsi heteroskedastisitas dengan white heteroscedasticity test dan weighted least squares.Dalam analisis regresi berganda, penting diselidiki adanya penyimpangan asumsi-asumsi, salah satunya asumsi homoskedastisitas. Apabila asumsi ini tak terpenuhi berarti terjadi heteroskedastisitas dan tidak lagi mempunyai sifat BLUE (Best Linear Unbiased Estimator). Dalam hal ini BLUE akan diperoleh dengan weighted least squares. Hasil menunjukkan bahwa white heteroscedasticity test dari data yang ditransformasi dengan weighted least squares menghasilkan nilai probability chi-squares sebesar 0,3301 pada level 5\%, maka model regresi berganda tersebut telah memenuhi asumsi homoskedastisitas.
\end{abstract}

Kata kunci : Heteroskedastisitas, Weighted Least Squares, White Heteroscedasticity Test

\section{Heteroscedasticity Analyze on the Cross Section Data with White Heteroscedasticity Test and Weighted Least Squares}

\begin{abstract}
The purpose of this study is to analyze and resolve the violation of heteroscedasticity assumption with white heteroscedasticity test and weighted least squares. In a multiple regression analysis, it is important investigated fort deviation assumptions, one of them heteroscedasticity assumption. If this assumption isn't fulfilled means there heteroscedasticity and no longer have BLUE properties. In this case the BLUE will be obtained by Weighted Least Squares. The results showed that the White Heteroscedasticity Test of transformed data with Weighted Least Squares produce Probability Chi-square value is 0.4064 at level 5\%, then the multiple regression model has fulfilled heteroscedasticity assumptions.
\end{abstract}

Keywords : Heteroscedasticity, Weighted Least Squares, White Heteroscedasticity Test

\section{Pendahuluan}

Dalam analisis regresi harus memperhatikan beberapa asumsi, yaitu multikolinearitas, heteroskedastisitas, autokorelasi dan linearitas. Namun dalam penelitian ini kita akan menggunakan uji asumsi heteroskedastisitas dimana terjadi perbedaan varians dari error suatu pengamatan ke pengamatan lain. Pendeteksian ada tidaknya masalah heteroskedastisitas dapat dilakukan antara lain dengan metode grafik atau menggunakan uji statistik, yaitu Uji Korelasi Rank Spearman, Uji Goldfeld-Quandt, Uji Park, Uji Glejser, dan Uji White. Namun dalam penelitian ini kita akan menggunakan Uji White, karena dengan Uji White kita akan meregresikan error kuadrat dengan variabel bebas [1].

Secara statistik, jika suatu kasus terjadi heteroskedastisitas maka dapat mengganggu model yang akan diestimasi. Cara mengatasi masalah heteroskedastisitas dapat dilakukan dengan transformasi data [2]. Untuk itu diperlukan metode alternatif untuk mengatasi masalah tersebut, yaitu dengan menggunakan metode kuadrat terkecil tertimbang (Weighted Least Squares). Data yang digunakan dalam penelitian ini adalah data sekunder yang diambil dari buku "Mengolah Data Statistik dengan Mudah Menggunakan Minitab 14" Iriawan (2006:231). Dimana data tersebut merupakan data kandungan rokok yang terdiri dari satu variabel tak bebas dan tiga variabel bebas. 
Adapun tujuan dari penelitian ini adalah untuk menganalisis pelanggaran asumsi heteroskedastisitas dengan White Heteroscedasticity Test pada data cross section dan untuk mengatasi pelanggaran asumsi heteroskedastisitas dengan Weighted Least Squares.

\section{Model Regresi Linier Berganda}

Secara umum model regresi berganda dengan variabel dependen $(\mathrm{Y})$ yang merupakan fungsi linear dari $p$ variabel independen $\left(\mathrm{X}_{1}, \mathrm{X}_{2}, \ldots, \mathrm{X}_{\mathrm{p}}\right)$, dapat ditulis [1] :

$$
Y=\beta_{0}+\beta_{1} X_{1}+\beta_{2} X_{2}+\cdots+\beta_{p} X_{p}+\varepsilon
$$

Salah satu asumsi penting yang harus dipenuhi adalah asumsi homoskedastisitas (homoscedastycity). Homoskedastisitas berarti bahwa varian dari error bersifat konstan. Asumsi ini menyatakan peubah respon memiliki varian yang sama sepanjang nilai peubah bebas. Pelanggaran terhadap asumsi homoskedastisitas disebut dengan heteroskedastisitas (heteroscedasticity) [3].

\subsection{Model Regresi Linear Dalam Pendekatan Matriks}

Model regresi linear dengan variabel dependen $Y$ dan $p$ variabel independen $\mathrm{X}_{1}, \mathrm{X}_{2}, \ldots, \mathrm{X}_{\mathrm{p}}$, secara umum dapat ditulis sebagai berikut [1]:

$$
Y_{i}=\beta_{0}+\beta_{1} X_{1 i}+\beta_{2} X_{2 i}+\cdots+\beta_{p} X_{p i}+\varepsilon_{i}
$$

Dengan $\beta_{0}$ adalah intercept, $\beta_{1}$ sampai $\beta_{p}$ adalah koefisien regresi, $\varepsilon_{i}$ faktor gangguan dan $i$ adalah pengamatan ke-i, serta $\mathrm{n}$ adalah ukuran sampel. Oleh karena $i$ merupakan pengamatan ke- $i$, maka terdapat n persamaan:

$$
\begin{aligned}
& Y_{1}=\beta_{0}+\beta_{1} X_{11}+\beta_{2} X_{21}+\cdots+\beta_{p} X_{p 1}+\varepsilon_{1} \\
& Y_{2}=\beta_{0}+\beta_{1} X_{12}+\beta_{2} X_{22}+\cdots+\beta_{p} X_{p 2}+\varepsilon_{2} \\
& Y_{3}=\beta_{0}+\beta_{1} X_{13}+\beta_{2} X_{23}+\cdots+\beta_{p} X_{p 3}+\varepsilon_{3} \\
& Y_{n}=\beta_{0}+\beta_{1} X_{1 n}+\beta_{2} X_{2 n}+\cdots+\beta_{p} X_{p n}+\varepsilon_{n}
\end{aligned}
$$

Persamaan (3) dapat kita tulis dalam bentuk matriks :

$$
\left[\begin{array}{c}
Y_{1} \\
Y_{2} \\
Y_{3} \\
\ldots \\
Y_{n}
\end{array}\right]=\left[\begin{array}{ccccc}
1 & X_{11} & X_{12} & \ldots & X_{p 1} \\
1 & X_{12} & X_{22} & \ldots & X_{p 2} \\
1 & X_{13} & X_{23} & \ldots & X_{p 3} \\
\ldots & \ldots & \ldots & \ldots & \ldots \\
1 & X_{1 n} & X_{2 n} & \ldots & X_{p n}
\end{array}\right]\left[\begin{array}{c}
\beta_{0} \\
\beta_{1} \\
\beta_{2} \\
\ldots \\
\beta_{p}
\end{array}\right]+\left[\begin{array}{c}
\varepsilon_{1} \\
\varepsilon_{2} \\
\varepsilon_{3} \\
\ldots \\
\varepsilon_{n}
\end{array}\right]
$$

Urutan atau orde matriks dan vektor dari persamaan (5) adalah :

$$
Y=(n \times 1), \quad X=[n \times(p+1)], \quad \beta=[(p+1) \times 1], \text { dan } \varepsilon=(n \times 1)
$$

\subsection{Koefisien Determinasi}

Koefisien determinasi $\left(\mathrm{R}^{2}\right)$ adalah suatu indikator yang digunakan untuk menggambarkan berapa banyak variasi yang dijelaskan dalam model. Berdasarkan nilai $R^{2}$ dapat diketahui tingkat signifikansi atau kesesuaian hubungan antara variabel bebas dan variabel tak bebas dalam regresi linier. Nilai $\mathrm{R}^{2}$ dapat dicari dengan menggunakan rumus [4]:

$$
R^{2}=\frac{b_{1} \sum X_{1} Y+b_{2} \sum X_{2} Y+\ldots+b_{n} \sum X_{n} Y}{\sum Y^{2}}
$$

\subsection{Standar Deviasi}

Standar deviasi adalah suatu nilai yang menunjukkan tingkat variasi kelompok data atau ukuran standar penyimpangan dari meannya. Rumus standar deviasi populasi untuk data tunggal [5] :

$$
\sigma=\sqrt{\frac{\sum(X i-\bar{X})^{2}}{n}}
$$




\subsection{Varians}

Varians adalah kuadrat dari standar deviasi. Simbol varians untuk populasi adalah $\sigma^{2}$ atau $\sigma^{2}$. Varians populasi untuk data tunggal [5]:

$$
\sigma^{2}={\frac{\Sigma(X i-\bar{X})^{2}}{n}}^{2}
$$

\section{Pengertian Heteroskedastisitas}

Homogenitas varian (varian konstan) ini dikenal sebagai "homoskedastisitas" (homoscedasticity). Ada kasus dimana seluruh faktor gangguan tidak memiliki varian yang sama (varian tidak konstan). Kondisi varian nir-konstan atau varian nir-homogen ini disebut "heteroskedastisitas" (heteroscedasticity). Jadi, U adalah heteroskedastisitas bila $\operatorname{Var}\left(\mathrm{U}_{\mathrm{i}}\right) \neq \sigma_{\mathrm{i}}^{2}$ (suatu nilai konstan) tapi $\operatorname{Var}\left(\mathrm{U}_{\mathrm{i}}\right)=\sigma_{\mathrm{i}}^{2}$ (suatu nilai yang bervariasi) [6].

\subsection{Sifat-Sifat Dari Heteroskedastisitas}

Dalam keadaan homoskedastik, varian dari $Y$ sama, yaitu $\operatorname{Var}\left(Y_{i}\right)=\operatorname{Var}\left(\varepsilon_{i}^{2}\right)=\sigma^{2}$. Akan tetapi dalam keadaan heteroskedastik, varianY tak sama, yaitu $\operatorname{Var}\left(\mathrm{Y}_{\mathrm{i}}\right)=\operatorname{Var}\left(\varepsilon_{\mathrm{i}}^{2}\right)=\sigma_{\mathrm{i}}^{2}$. Ini berarti bahwa varian $\left(\mathrm{Y}_{\mathrm{i}}\right)$ atau varian $\left(\varepsilon_{\mathrm{i}}\right)$ dengan syarat bahwa $\mathrm{X}=\mathrm{X}_{\mathrm{i}}$, tak sama untuk $\mathrm{X}$ yang berlainan [2].

\subsection{Konsekuensi Sebagai Akibat Adanya Heteroskedastisitas}

Jika semua asumsi klasik tersebut berlaku, kecuali satu yang tidak, yaitu terjadinya heteroskedastisitas, maka pemerkira Ordinary Least Squares masih tetap tak bias dan konsisten akan tetapi tidak lagi efisien baik untuk sampel kecil maupun untuk sampel besar. Untuk lebh jelasnya perhatikan model regresi dua variabel berikut:

$$
\mathrm{Y}_{\mathrm{i}}=\mathrm{A}+\mathrm{BX}_{\mathrm{i}}+\varepsilon_{\mathrm{i}}
$$

Sekarang varian $\left(\varepsilon_{\mathrm{i}}\right)=\mathrm{E}\left(\varepsilon_{\mathrm{i}}^{2}\right)=\sigma_{\mathrm{i}}^{2}$. Maka akan dapat ditunjukkan dengan metode kuadrat terkecil tertimbang (weighted least squares). Dapat diperoleh BLUE dari parameter $\mathrm{B}$, yaitu $\mathrm{b}^{*}$, dengan rumus sebagai berikut :

dan variannya :

$$
b^{*}=\frac{\left(\Sigma W_{i}\right)\left(\Sigma W_{i} X_{i} Y_{i}\right)-\left(\Sigma W_{i} X_{i}\right)\left(\Sigma W_{i} Y_{i}\right)}{\left(\Sigma W_{i}\right)\left(\Sigma W_{i} X_{i}^{2}\right)-\left(\Sigma W_{i} X_{i}\right)^{2}}
$$

dimana :

$$
\operatorname{Var}\left(b^{*}\right)=\frac{\Sigma W_{i}}{\left(\Sigma W_{i}\right)\left(\Sigma W_{i} X_{i}^{2}\right)-\left(\Sigma W_{i} X_{i}\right)^{2}}
$$

$$
\mathrm{W}_{\mathrm{i}}=1 / \sigma_{\mathrm{i}}^{2}
$$

Pemerkira $b^{*}$ disebut pemerkira kuadrat terkecil tertimbang (weighted least squares estimator) [2].

\subsection{Pendeteksian Heteroskedastisitas}

Pengujian heteroskedastisitas dapat dideteksi dengan uji White. Uji White dapat dilakukan dengan meregresikan residual kuadrat dengan variabel independen dan variabel independen kuadrat dengan perkalian [7].Ada beberapa metode baik formal maupun informal yang dapat mendeteksi adanya heteroskedastisitas.

1. Sifat persoalannya. Seringkali, sifat persoalan yang diteliti menyarankan atau menunjukkan kemungkinan adanya heteroskedastisitas.

2. Metode grafik. Apabila tak ada informasi sebelumnya atau informasi secara empiris tentang adanya heteroskedastisitas dalam prakteknya kita dapat membuat analisis regresi berdasarkan asumsi bahwa tidak ada heteroskedastisitas dan kemudian melakukan pengecekan terhadap perkiraan kesalahan pengganggu kuadrat yaitu $e_{i}$, untuk melihat kalau seluruh $e_{i}$ menunjukkan pola yang sistematis [2].

Cara informal untuk mengetahui adanya heteroskedastisitas adalah dengan membuat grafik residual. Cara formal untuk mendeteksi ada tidaknya heteroskedastisitas pada model regresi adalah dengan menggunakan uji White. Perhatikan persamaan berikut [8] :

$$
Y_{i}=\beta_{0}+\beta_{1} X_{1 i}+\beta_{2} X_{2 i}+\cdots+\beta_{p} X_{p i}+\varepsilon_{i}
$$


Berdasarkan model regresi diatas, uji White dapat dilakukan dengan beberapa prosedur, yaitu:

1. Hasil estimasi dari model regresi akan menghasilkan nilai error yaitu $\hat{\varepsilon}_{i}^{2}$

2. Buat persamaan regresi:

$$
\widehat{U}_{i}^{2}=\alpha_{0}+\alpha_{1} X_{1 i}+\alpha_{2} X_{2 i}+\alpha_{3} X_{1 i}^{2}+\alpha_{4} X_{2 i}^{2} \ldots+\alpha_{p} X_{p i}^{2}+\varepsilon_{i}
$$

Perhatikan model diatas, uji ini mengasumsikan bahwa varian error merupakan fungsi yang mempunyai hubungan dengan variabel bebas, kuadrat masing-masing variabel bebas dan interaksi antara variabel bebas.

3. Formulasi hipotesis:

$\mathrm{H}_{0}$ : tidak terdapat masalah heteroskedastisitas dalam model regresi

$\mathrm{H}_{1}$ : terdapat masalah heteroskedastisitas dalam model regresi

4. Sampel berukuran $n$ dan koefisien determinasi $R^{2}$ yang didapat dari regresi akan mengikuti distribusi Chi-Square dengan derajat bebas jumlah variabel bebas atau jumlah konferensi regresi diluar intercept. Dengan demikian formulasi uji White adalah:

$$
n R^{2} \approx \chi^{2}
$$

Jika nilai perhitungan melebihi nilai kritis dengan $\alpha$ yang dipilih, diputuskan bahwa tidak terdapat heteroskedastisitas. Hal ini disebabkan $\alpha_{1}=\alpha_{2}=\alpha_{3}=\alpha_{4}=0$ sehingga, $\widehat{U}_{i}^{2}=\alpha_{0}$ (konstan).

\subsection{Cara Mengatasi Persoalan Heteroskedastisitas}

Apabila $\sigma_{i}^{2}$ diketahui atau dapat diperkirakan, cara yang paling mudah untuk mengatasi adanya heteroskedastisitas ialah dengan metode kuadrat terkecil tertimbang (weighted least squares). Metode kuadrat terkecil tertimbang sudah memperhitungkan adanya nilai $\mathrm{e}_{\mathrm{i}}$ yang ekstrim. Untuk membuat minimum digunakan rumus :

$$
\Sigma e_{i}=\Sigma W_{i}\left(Y_{i}-a^{*}-b^{*} X_{i}\right)^{2}
$$

Dimana $\mathrm{W}_{\mathrm{i}}=$ timbangan (weight), $\mathrm{a}^{*}$ dan $\mathrm{b}^{*}$ adalah penduga metode kuadrat terkecil tertimbang. Kalau $\sigma_{\mathrm{i}}$ diketahui, maka timbangan $\mathrm{W}_{\mathrm{i}}$ akan mengambil nilaiW $\mathrm{W}_{\mathrm{i}}=1 / \sigma_{\mathrm{i}}$, yang berarti timbangan setiap observasi proporsional terbalik dari $\sigma_{\mathrm{i}}$. Timbangan ini akan mengurangi secara tajam pengaruh nilai observasi ekstrim. Metode kuadrat terkecil tertimbang membuat minimum:

$$
\sum \mathrm{W}_{\mathrm{i}} \mathrm{e}_{\mathrm{i}}^{2}=\sum \mathrm{W}_{\mathrm{i}}\left(\mathrm{Y}_{\mathrm{i}}-\mathrm{a}^{*}-\mathrm{b}^{*} \mathrm{X}_{\mathrm{i}}\right)^{2}
$$

Dimana $a^{*}$ dan $b^{*}$ merupakan pemerkira kuadrat terkecil dengan timbangan $W_{i}=1 / \sigma_{i}^{2}$, yaitu timbangan $\mathrm{W}_{\mathrm{i}}$ proporsional terbalik dari varian $\varepsilon_{\mathrm{i}}$ atau $\mathrm{Y}_{\mathrm{i}}$ dengan syarat bahwa $\mathrm{X}=\mathrm{X}_{\mathrm{i}}$, perlu diketahui bahwa varian $\left(\varepsilon_{\mathrm{i}} / \mathrm{X}_{\mathrm{i}}\right)=$ varian $\left(\mathrm{Y}_{\mathrm{i}} / \mathrm{X}_{\mathrm{i}}\right)=\sigma_{\mathrm{i}}^{2}$. Heteroskedastisitas dapat diselesaikan apabila dianggap atau diasumsikan bahwa varian $(\mathrm{e})=\mathrm{h} \mathrm{X}_{\mathrm{i}}^{2}$, dimana $\mathrm{h}=$ konstan, tak sama dengan nol $(h \neq 0)$, kita dapat mengoreksi adanya heteroskedastisitas dengan jalan membagi setiap suku di dalam regresi baru dengan variabel yang sudah diubah bentuknya (transformed variables). Untuk hubungan dua variabel atau regresi sederhana bentuknya sebagai berikut :

$$
\mathrm{Y}_{\mathrm{i}} / \mathrm{X}_{\mathrm{i}}=\mathrm{A} / \mathrm{X}_{\mathrm{i}}+\mathrm{B}+\mathrm{e} / \mathrm{X}_{\mathrm{i}}
$$

Kesalahan pengganggu sekarang menjadi $\mathrm{e} / \mathrm{X}_{\mathrm{i}}$ dan variannya menjadi homoskedastik, yaitu:

$$
\operatorname{Var}\left(e_{i} / X_{i}\right)^{2}=1 / X_{i}^{2} \operatorname{Var}\left(e_{i}\right)^{2}=1 / X_{i}^{2} h \cdot X_{i}^{2}=h
$$

Perlu diperhatikan, titik potong yang asli berubah menjadi variable setelah dibagi dengan $X_{i}$, yaitu $\mathrm{A} / \mathrm{X}_{\mathrm{i}}$, sedangkan koefisien regresi $\beta$ sekarang memegang peranan sebagai titik potong yang baru. Di dalam membuat interpretasi harus berhati-hati mengenai regresi yang ditimbang, berdasarkan variabel yang sudah dirubah (transformed). Di dalam hal regresi berganda, lebih dari satu variabel bebas, setiap suku dalam regresi dibagi dengan salah satu variabel bebas yang berkorelasi kuat. Berikut adalah contoh persamaan :

Setelah ditransformasi :

$$
\mathrm{Y}_{\mathrm{i}}=\mathrm{B}_{0}+\mathrm{B}_{1} \mathrm{X}_{1 \mathrm{i}}+\mathrm{B}_{2} \mathrm{X}_{2 \mathrm{i}}+\mathrm{e}_{\mathrm{i}}
$$

$$
\mathrm{Y}_{\mathrm{i}} / \mathrm{X}_{2 \mathrm{i}}=\mathrm{B}_{0} / \mathrm{X}_{2 \mathrm{i}}+\mathrm{B}_{1} \mathrm{X}_{1 \mathrm{i}} / \mathrm{X}_{2 \mathrm{i}}+\mathrm{B}_{2}+\mathrm{e}_{\mathrm{i}} / \mathrm{X}_{2 \mathrm{i}}
$$

Perhatikan untuk persamaan yang ditimbang, titik potong $\mathrm{B}_{0}$ berubah menjadi variabel $\mathrm{B}_{0} / \mathrm{X}_{2 \mathrm{i}}$, sedangkan koefisien regresi $\mathrm{B}_{2}$ berubah menjadi titik potong [2]. 


\section{Metodologi Penelitian}

\subsection{Waktu dan Tempat Penelitian}

Penelitian ini telah dilaksanakan dari bulan Maret sampai Mei 2015 di Jurusan Matematika FMIPA Universitas Sam Ratulangi.

\subsection{Sumber Data}

Data yang digunakan dalam penelitian ini adalah data sekunder yang diambil dari buku "Mengolah Data Statistik dengan Mudah Menggunakan Minitab 14" Iriawan (2006:231). Data yang terdapat dalam buku ini adalah data mengenai kandungan rokok dengan jumlah pengamatan sebanyak 25 buah pengamatan. Peubah terikat (Y) yang digunakan adalah Karbon monoksida, kemudian peubah bebasnya adalah Nikotin $\left(\mathrm{X}_{1}\right)$, Tar $\left(\mathrm{X}_{2}\right)$, dan Berat rokok $\left(\mathrm{X}_{3}\right)$.

\subsection{Langkah-langkah Pengolahan Data}

Pengolahan data pada penelitian ini menggunakan bantuan komputer. Tahapan pengolahan datanya adalah sebagai berikut :

1. Melakukan estimasi metode kuadrat terkecil (ordinary least squares).

2. Membuat uji formal dan uji nonformal untuk melihat apakah terdapat masalah heteroskedastisitas baik dalam bentuk grafik maupun dengan uji White.

3. Jika terdapat masalah heteroskedastisitas, maka akan dilakukan tindakan perbaikan pada model regresi linier berganda dengan cara mentransformasikan variabel.

4. Melakukan estimasi metode kuadrat terkecil tertimbang (wieghted least squares) menggunakan prosedur metode kuadrat terkecil terhadap data yang ditransformasi.

5. Menganalisis kembali dengan uji White untuk melihat apakah masih terdapat masalah heteroskedastisitas dalam model regresi.

\section{Hasil Dan Pembahasan}

\subsection{Model Regresi}

Berdasarkan sumber data yang diambil dari buku "Mengolah Data Statistik dengan Mudah Menggunakan Minitab 14" Iriawan (2006:231), terdapat 25 observasi tentang kandungan dalam rokok. Dalam data ini, terdapat tiga variabel bebas dan satu variabel tak bebas.Variabel bebas diantaranya adalah kandungan nikotin, kandungan tar, dan berat rokok, sedangkan variabel tak bebas adalah jumlah karbon monoksida. Hasil estimasi dengan metode kuadrat terkecil (ordinary least squares) disajikan pada tabel berikut:

Tabel 1. Hasil estimasi model regresi Ordinary Least Squares

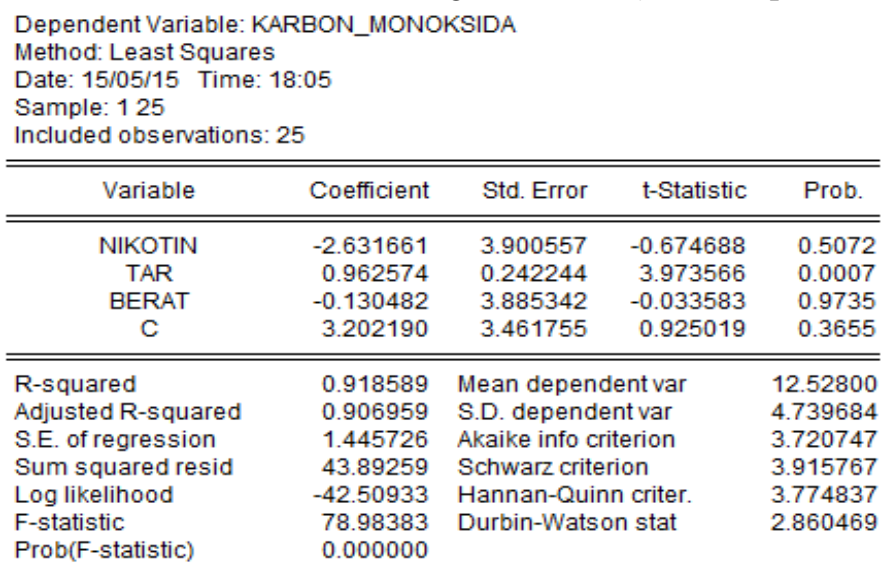

Dari ketiga variabel bebas tersebut terdapat satu variabel yang berpengaruh signifikan terhadap variabel $\mathrm{Y}$, yaitu variabel $\mathrm{X} 2$, hal ini dikarenakan probability t statistik pada $\mathrm{X} 2<\alpha$ pada level $5 \%$, yaitu $0.0007<0.05$, sedangkan variabel X1 dan X3 tidak berpengaruh signifikan 
terhadap variabel $\mathrm{Y}$, dikarenakan probability $\mathrm{t}$ statistik pada $\mathrm{X} 1$ dan $\mathrm{X} 2>\alpha$ pada level 5\%, yaitu $0.5072>0.05$ dan $0.9735>0.05$. Hasil estimasi ordinary least squares antara kandungan karbon monoksida dengan variabel-variabel yang mempengaruhinya adalah:

$$
\mathrm{Y}=3.202-2.631 \mathrm{X}_{1}+0.962 \mathrm{X}_{2}-0.130 \mathrm{X}_{3}
$$

\subsection{Uji Formal (White Heteroskedasticity Test)}

Langkah-langkah pengujian melalui uji White adalah sebagai berikut :

1. Mengestimasi model persamaan sehingga mendapat nilai errornya

2. Membuat persamaan regresi

$\mathrm{Y}=3.202-2.631 \mathrm{X}_{1}+0.962 \mathrm{X}_{2}-0.130 \mathrm{X}_{3}+\mathrm{e}$

3. Formulasi hipotesis

$\mathrm{H}_{0}$ : Homoskedastisitas

$\mathrm{H}_{1}$ : Heteroskedastisitas

Dengan $\alpha=5 \%=0.05$

4. Formulasi uji White

Prob Obs*R-square < 0.05 , Maka ada heteroskedastisitas

Prob Obs*R-square $>0.05$, Maka tidak ada heteroskedastisitas

5. Kesimpulan hasil uji White dengan bantuan computer disajikan pada tabel berikut :

Tabel 2. Hasil output White Heteroscedasticity Test pada data awal Heteroskedasticity Test: White

\begin{tabular}{llll}
\hline \hline F-statistic & 4.652607 & Prob. F(9,15) & 0.0044 \\
Obs*R-squared & 18.40641 & Prob. Chi-Square(9) & 0.0307 \\
Scaled explained SS & 10.20521 & Prob. Chi-Square(9) & 0.3341 \\
\hline \hline
\end{tabular}

Hasil output menunjukkan bahwa nilai Prob Obs*R-Squared lebih kecil dari $\alpha(0.0307<0.05)$. Jadi dapat disimpulkan bahwa hipotesis nol ditolak karena dalam model regresi linear berganda telah terjadi penyimpangan asumsi heteroskedastisitas.

\subsection{Uji Nonformal Scatterplot}

Analisa model regresi berdasarkan asumsi bahwa pada model regresi tidak boleh terjadi penyimpangan asumsi. Gambar plot yang dibuat dengan estimasi metode kuadrat terkecil (ordinary least squares) disajikan pada gambar berikut :

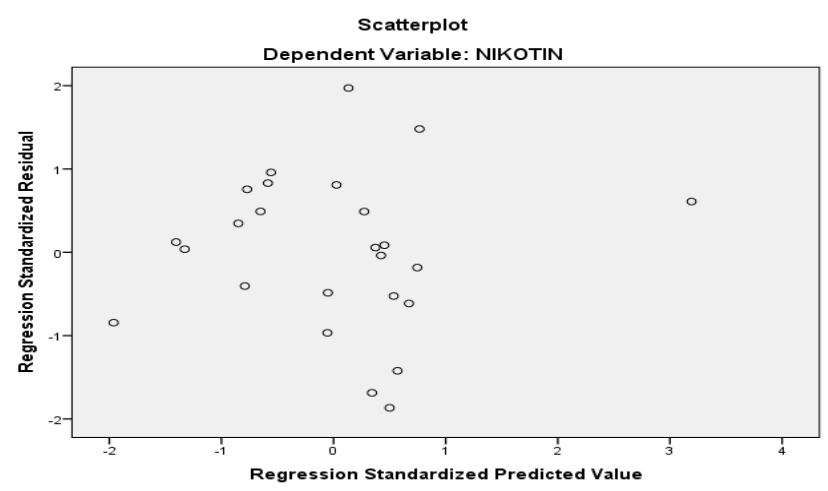

Gambar 1. Hasil output Scatterplot

Peningkatan nilai error pada sumbu X diikuti dengan keragaman yang meningkat pada sumbu Y. Dari pola tersebut terlihat bahwa varians error tidak konstan. Jadi, dalam model persamaan regresi tersebut telah terdapat penyimpangan asumsi heteroskedastisitas yang mengakibatkan estimasi metode kuadrat terkecil (ordinar least squares) menjadi tidak efisien, sehingga prediksi model yang dibuat tidak dapat diandalkan. 


\subsection{Mengatasi Pelanggaran Asumsi Heteroskedastisitas}

Suatu asumsi yang kritis dari model regresi linear klasik ialah bahwa kesalahan pengganggu $e_{i}$ semuanya harus mempunyai varian yang sama. Apabila asumsi ini tak terpenuhi berarti terjadi heteroskedastisitas dan tidak lagi mempunyai sifat BLUE (Best Linear Unbiased Estimator). Dalam hal ini BLUE akan diperoleh apabila dipergunakan metode kuadrat terkecil tertimbang (weighted least squares). Namun sebelum membuat estimasi dengan weighted least squares, akan dilakukan transformasi pada model yang asli, yaitu transformasi variabel, sehingga model yang telah ditransformasikan tersebut akan menghasilkan kesalahan pengganggu yang mempunyai varian tetap/konstan, sehingga akan tercapai keadaan yang homoskedastisitas. Hasil estimasi metode kuadrat terkecil tertimbang (weighted least squares) pada data yang telah di transformasi disajikan pada tabel berikut :

Tabel 3. Hasil estimasi model regresi Weighted Least Squares

\begin{tabular}{|c|c|c|c|c|}
\hline $\begin{array}{l}\text { Dependent Variable: } \\
\text { Method: Least Squar } \\
\text { Date: } 24 / 07 / 15 \text { Time } \\
\text { Sample: } 125 \\
\text { Included observation } \\
\text { Weighting series: } X 2 \\
\text { Weight type: Variance } \\
\text { White heteroskedast }\end{array}$ & $\begin{array}{l}45 \\
\text { erage scalin } \\
\text { consistent st }\end{array}$ & andard errors & covariance & \\
\hline Variable & Coefficient & Std. Error & t-Statistic & Prob. \\
\hline $\mathrm{x} 1$ & -3.177246 & 2.272846 & -1.397915 & 0.1767 \\
\hline $\mathrm{x} 2$ & 1.090451 & 3.955367 & 0.275689 & 0.7855 \\
\hline x3 & 4.717772 & 3.184159 & 1.481638 & 0.1533 \\
\hline C & 0.847481 & 0.233498 & 3.629501 & 0.0016 \\
\hline \multicolumn{5}{|c|}{ Weighted Statistics } \\
\hline R-squared & 0.580278 & \multirow{2}{*}{\multicolumn{2}{|c|}{$\begin{array}{l}\text { Mean dependent var } \\
\text { S.D. dependent var }\end{array}$}} & 1.082098 \\
\hline Adjusted R-squared & 0.520318 & & & 0.200864 \\
\hline S.E. of regression & 0.114199 & \multicolumn{2}{|c|}{ Akaike info criterion } & -1.356099 \\
\hline Sum squared resid & 0.273871 & \multicolumn{2}{|c|}{ Schwarz criterion } & -1.161078 \\
\hline Log likelihood & 20.95123 & \multicolumn{2}{|c|}{ Hannan-Quinn criter. } & -1.302008 \\
\hline F-statistic & 9.677722 & \multicolumn{2}{|c|}{ Durbin-Watson stat } & 2.876372 \\
\hline Prob(F-statistic) & 0.000327 & \multicolumn{2}{|c|}{ Weighted mean dep. } & 1.087919 \\
\hline \multicolumn{5}{|c|}{ Unweighted Statistics } \\
\hline R-squared & 0.539492 & \multirow{3}{*}{\multicolumn{2}{|c|}{$\begin{array}{l}\text { Mean dependent var } \\
\text { S.D. dependent var } \\
\text { Sum squared resid }\end{array}$}} & 1.078659 \\
\hline Adjusted R-squared & 0.473705 & & & 0.158509 \\
\hline S.E. of regression & 0.114992 & & & 0.277688 \\
\hline
\end{tabular}

Berdasarkan output diatas, dapat dilihat bahwa sekarang model regresi tersebut telah memiliki persamaan regresi yang baru yaitu:

$$
\mathrm{Y}=0.847-3.177 \mathrm{X}_{1}+1.090 \mathrm{X}_{2}+4.717 \mathrm{X}_{3}
$$

Selanjutnya kita akan melakukan pendeteksian lagi dengan uji White, untuk melihat apakah dalam model regresi masih terdapat penyimpangan asumsi heteroskedastisitas atau tidak. Hasil uji White yang dibuat pada data yang sudah di transformasi disajikan pada tabel berikut :

Tabel 4. Hasil output White Heteroscedasticity Test pada data transformasi

\begin{tabular}{llll}
\multicolumn{4}{l}{ Heteroskedasticity Test: White } \\
\hline \hline F-statistic & 0.996777 & Prob. F(10,14) & 0.4890 \\
Obs*R-squared & 10.39706 & Prob. Chi-Square(10) & 0.4064 \\
Scaled explained SS & 5.336789 & Prob. Chi-Square(10) & 0.8676 \\
\hline
\end{tabular}

Hasil output dari uji White diatas, dapat dilihat bahwa nilai Prob Obs*R-Squared lebih besar dari $\alpha(0.4064>0.05)$. Dengan demikian, dapat disimpulkan bahwa hipotesis nol di terima. Artinya pada model regresi telah terjadi keadaan yang homoskedastisitas dan tidak lagi terjadi penyimpangan asumsi heteroskedastisitas, sehingga terpenuhi sifat BLUE yang mengakibatkan model tersebut menjadi efisien kembali dan kesimpulan yang diambil menjadi menentu.

\subsection{Analisis Perbandingan White Heteroskedasticity Test}

Berikut akan disajikan perbandingan dari hasil estimasi metode kuadrat terkecil (ordinary least squares) dengan metode kuadrat terkecil tertimbang (weighted least squares). 
Tabel 5. Perbandingan White Heteroscedasticity Test OLS dengan WLS

\begin{tabular}{|c|c|}
\hline $\begin{array}{c}\text { Uji White Data Awal } \\
(\text { Ordinary Least Squares })\end{array}$ & $\begin{array}{c}\text { Uji White Data Transformasi } \\
\text { (Weighted Least Squares })\end{array}$ \\
\hline Probability Chi-Square $(0.0307<0.05)$ & Probability Chi-Square $(0.4064>0.05)$ \\
\hline Heteroskedastisitas & Homoskedastisitas \\
\hline
\end{tabular}

Berdasarkan hasil perbandingan dari dua estimasi di atas, terlihat bahwa setelah data ditransformasi dan dilakukan kembali uji white, maka nilai probabilitas chi-square lebih besar dari $\alpha(0.4064>0.05)$. Jadi, dapat disimpulkan bahwa setelah data ditransformasi menggunakan metode Weighted Least Squares, maka model regresi berganda tersebut telah memenuhi asumsi homoskedastisitas.

\section{Kesimpulan}

Berdasarkan hasil analisis data kandungan rokok yang digunakan dalam penelitian ini, setelah dilakukan estimasi ordinary least squares dan white heteroscedasticity test, didapati bahwa model regresi linear berganda pada data cross section tersebut tidak memenuhi asumsi homoskedastisitas, berarti ada pelanggaran asumsi heteroskedastisitas yang mengakibatkan model regresi tersebut tidak efisien. Jadi, Persoalan heteroskedastisitas dapat diatasi dengan weighted least squares.

\section{Daftar Pustaka}

[1] Quadratullah, M. 2012. Analisis Regresi Terapan Teori, Contoh Kasus, dan Aplikasi dengan SPSS. ANDI. Yogyakarta.

[2] Supranto, J. 1984. Ekonometrik Jilid Dua. LPFEUI. Jakarta.

[3] Uthami, I. 2013. Regresi Kuantil Median Untuk Mengatasi Heteroskedastisitas Pada Analisis Regresi. E-Jurnal Matematika. 1(2): 6 - 13.

[4] Sinambela, S. 2014. Menentukan Koefisien Determinasi Antara Estimasi Dengan Type Welsch Dengan Least Trimmed Square Dalam data Yang Mempunyai Pencilan. Jurnal Sains Matematika (2337-9197). 3(2) : 225-235.

[5] Buchari, H. 2014. Pengantar Statistika Sosial. ALFABETA. Bandung.

[6] Sumodiningrat, G. 1994. Ekonometrika Pengantar. BPFE. Yogyakarta.

[7] Udayani, D. 2013. Pengaruh Profitabilitas dan Investment Opportunity Set Pada Struktur Modal. E-Jurnal (2302-8556). 4(2) : 299 - 314.

[8] Nachrowi, dkk. 2006. Pendekatan Populer dan Praktis Ekonometrika Untuk Analisis Ekonomi dan Keuangan. FEUI. 